\title{
Importância das nascentes do Semiárido Alagoano no abastecimento das populações rurais difusas
}

\author{
Importance of Alagoas Semiarid sources in the supply of diffuse rural populations \\ SILVA ${ }^{1}$, L. C. S.; SILVA², A. P. L.; ALVES ${ }^{3}$, S. S.; SANTOS NETO ${ }^{4}$, P. \\ leila-caroline@hotmail.com
}

\begin{abstract}
Resumo
O abastecimento de água da Região Semiárida Brasileira sempre foi um desafio para a convivência das populações com a seca, do contingente populacional que habitam essas áreas as que mais sofrem com essa escassez no abastecimento são as populações rurais difusas. Com base nisso objetivo dessa pesquisa foi mapear municípios do Semiárido Alagoano com presença de nascentes, avaliar estado de conservação, e observar os usos dessas nascentes para o abastecimento das populações rurais. Para isso foi realizado Inicialmente foi realizado interpretação de imagens preexistentes; modelos de elevação de terreno; mapas hidrográficos; imagens de satélites, de alguns municípios selecionados, além de avaliação do estado de conservação. Inicialmente foram identificados treze municípios com presença de nascentes, mais de 50 nascentes, que é utilizada pela população, porém, passam processo de degradação.
\end{abstract}

\begin{abstract}
The water distribution in the semiarid region was always a challenge for the local population that lives in these dry climate. Of the big population that inhabits the area, the rural spread population is the one that suffer the most from this water scarcity. Based on that, the objective of the research was to map the towns in the in Alagoas state that occurs water springs, evaluate its current conservation condition, and to observe the uses of these springs in the supply of these local rural population. At first, in the interpretation of the area there were used aerial images, elevation models of the terrain and hidrographic maps, besides the evaluation of the current conditions. Initially there detectec thirteen towns with springs, and more than fifty spring that is used by the local population, however in a process of degradation.
\end{abstract}

Key words: Alagoas, water, water scarcity.

Palavras chave: Alagoas, água, escassez hídrica.

\section{INTRODUÇÃO}

A água é um recurso natural escasso e cuja disponibilidade tem sido limitada, principalmente nas regiões Áridas e Semiáridas (GHEYI et al., 2012). Na região Semiárida do Brasil a disponibilidade e usos da água continuam a ser uma questão crucial no que concerne seu desenvolvimento, é fato que grandes esforços vêm sendo desenvolvidos há séculos com o objetivo de implantar infraestruturas capazes de disponibilizar água suficiente para garantir o abastecimento humano, animal e viabilizar a irrigação (CIRILO, 2008), no entanto, esses esforços ainda são insuficientes.

A escassez natural de água dessa região somada à degradação dos recursos hídricos é mais problema que tem inviabilizado seus usos, e essa é a realidade de boa parte dos rios e nascentes do território brasileiro. O processo de degradação de nascentes tem se tornado cada dia mais comum 
devido a ocupações e manejos inadequados desses ambientes. Essa situação tem se agravado devido à dinâmica do crescimento populacional e ao desenvolvimento das fronteiras agropecuárias que se instalaram nos arredores dos cursos d'água (ARAÚJO; SILVA, 2013).

As nascentes são elementos de suma importância na dinâmica hidrológica, elas são focos da passagem da água subterrânea para a superfície (FELIPPE; MAGALHÃES JUNIOR, 2009) além de serem parcialmente responsáveis pela origem dos recursos hídricos, assim, as nascentes se tornaram um ponto crucial na preservação ambiental de qualquer região, considerando que água remete à sobrevivência e que sua escassez pode afetar de forma determinante a manutenção da vida (VIEL et al., 2013).

No Semiárido o principal problema ligado à água é que a demanda é superior à oferta, então o abastecimento fica limitado a quem pode pagar pelos custos, e por isso abastecimento convencional não consegue atender as populações rurais difusas por diversos motivos, principalmente pelas distâncias das moradias, restando a essas populações o abastecimento por meio de cisternas, carros pipas, açudes, dentre outros, que são importantes ferramentas de convivência com a seca, mas que nem sempre conseguem atender as necessidades reais dessas populações.

Para Campos (2012), o atendimento às populações difusas dos sertões constitui-se um dos grandes desafios sem solução fácil, então as nascentes passam a ser mais uma alternativa uma vez que ela é a forma mais fácil de acesso à água a maioria das populações, posto que os custos financeiros de utilização das águas superficiais quando captadas das nascentes podem ser consideravelmente menores (SILVA et al., 2014).

Portanto o objetivo dessa pesquisa foi mapear alguns municípios do Semiárido Alagoano com presença de nascentes, avaliar estado de conservação, e observar os usos dessas nascentes para o abastecimento das populações rurais.

\section{MATERIAL E MÉTODOS}

\subsection{Caracterização geral da área de estudo}

O Semiárido Brasileiro abrange uma área de 969.589,4 $\mathrm{km}^{2}$ onde estão inseridos 1.133 municípios, dos estados de Minas Gerais, Pernambuco, Ceará, Piauí, Paraíba, Bahia, Rio Grande do Norte, Sergipe e Alagoas. O Semiárido Alagoano está localizado a Oeste do estado de Alagoas, abrange 38 municípios correspondendo a 37,25\% do território, que estão inseridos nas mesorregiões do Sertão Alagoano e Agreste Alagoano. 


\section{SEMIÁRIDO ALAGOANO}

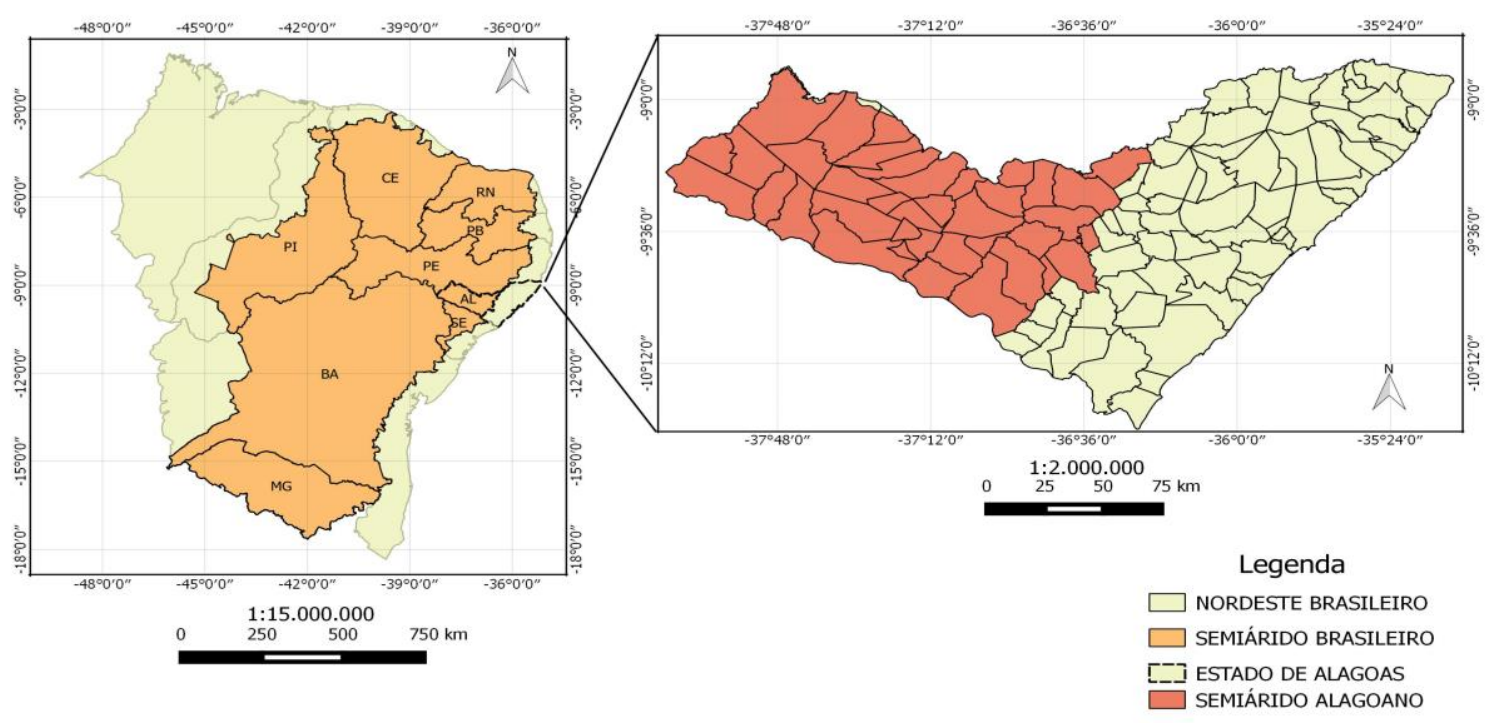

Figura 1. Mapa de localização do Semiárido Alagoano. Fonte. Paulo Santos Neto

No Semiárido Alagoano o clima predominante é o Semiárido BSh, com a presença de manchas de clima Subúmido seco Cfh e Árido B segundo a classificação de Köppen (SEPLANDE, 2014) com precipitação variando entre 400 a 900 mm ao ano (SEMARH, 2014) e temperaturas variando entre $17^{\circ} \mathrm{C}$ a $33^{\circ} \mathrm{C}$ (BARROS et al., 2012).

A vegetação predominante do tipo Caatinga Hiperxerófila caracterizada por vegetação arbustiva e pouco densa com forte intensidade de cactáceas e bromeliáceas (CORDEIRO; OLIVEIRA, 2010) e Caatinga Hipoxerofila caracterizadas pelo extrato arbustivo-arbóreo, com a maioria das espécies caducifólias e espinhentas, fazendo-se presentes também, espécies da mata úmida, o que lhe confere um caráter de transição entre estes biomas (ALVES, 2008).

Os solos com maior predominância são os Neossolos e Planossolos, também havendo a presença de pequenas manchas de Latossolos, Argissolos e Luvissolos (EMBRAPA, 2014). Os Neossolos são solos rasos pedregoso, pouco desenvolvidos, com fertilidade variada e sem horizonte $\mathrm{B}$ definido, já os Planossolos apresentam drenagem restrita, alta suscetibilidade à erosão, elevado risco de salinização, consistência dura a extremamente dura do horizonte B plânico, pequena profundidade efetiva e pedregosidade superficial (EMBRAPA, 2006).

As principais bacias hidrográficas do Semiárido Alagoano são as bacias do Ipanema, do Capiá, Talhada, Traipu, Riacho Grande, do Coruripe e do Piauí, além da Bacia do São Francisco de regime de vazão perene (SEMARH, 2014).

\subsection{Descrição da pesquisa}


Inicialmente foi realizado interpretação de imagens preexistentes; modelos de elevação de terreno; mapas hidrográficos; imagens de satélites, de alguns municípios selecionados. Logo após o levantamento desses dados foram realizadas visitas a campo a esses municípios buscando comprovar a veracidade desses dados obtidos. E por fim, foi confeccionado um mapa de localização dessas nascentes no Semiárido Alagoano com o software livre QGIS.

A avaliação do estado de conservação das nascentes foi realizado em campo aplicando-se o Índice de Impacto Ambiental Macroscópico (IIAM) de Gomes et al., (2005), que consiste na observação de onze parâmetros macroscópico que podem gerar impactos as nascentes (Cor da água, odor, lixo no entorno, materiais flutuantes, espumas, óleo, esgoto, vegetação, usos, acesso, equipamentos de captação de água).

\section{RESULTADOS E DISCUSSÃO}

O levantamento de dados permitiu identificar inicialmente 13 municípios do Semiárido Alagoano com presença de nascentes, chamando a atenção a grande quantidade de nascentes, mais de 50 distribuídas por esses municípios e também seus regimes de vazão perene, o que as tornam ainda mais importante, já que o normal para os recursos hídricos do Semiárido é a intermitência.

Outro dado importante relacionado aos municípios onde foram encontradas as nascentes é que a grande maioria de sua população total vive no meio rural, e mesmo os municípios que possuem maioria de sua população na zona urbana apresentam um grande contingente de moradores da zona rural o que as caracterizam como população rural difusa (Tabela 1).

Tabela 1. Relação entre a população urbana e população rural dos municípios do Semiárido Alagoano com presença de nascentes

\begin{tabular}{cccc}
\hline Municípios & População urbana & População Rural & População total \\
\hline Água Branca & $26 \%$ & $74 \%$ & 19.377 \\
Arapiraca & $85 \%$ & $15 \%$ & 214.006 \\
Belém & $41 \%$ & $59 \%$ & 4.551 \\
Limoeiro de Anadia & $8 \%$ & $92 \%$ & 26.992 \\
Maravilha & $50 \%$ & $50 \%$ & 10.284 \\
Mata Grande & $23 \%$ & $77 \%$ & 24.698 \\
Palmeira dos Índios & $73 \%$ & $27 \%$ & 70.368 \\
Pariconha & $27 \%$ & $73 \%$ & 10.264 \\
Poço das Trincheiras & $15 \%$ & $85 \%$ & 13.872 \\
Quebrangulo & $56 \%$ & $44 \%$ & 11.480 \\
Santana do Ipanema & $61 \%$ & $39 \%$ & 44.932 \\
Senador Rui Palmeira & $30 \%$ & $70 \%$ & 13.047 \\
Tanque D`arca & $35 \%$ & $65 \%$ & 6.122 \\
\hline
\end{tabular}

Fonte. Perfil Municipal de Alagoas 
Dados do IBGE (2010) evidenciam que a maior parte do abastecimento de água da população rural da região Semiárida Brasileira se dá em sua maioria por meio de poços ou nascentes, inclusive em Alagoas, sendo 32,7\% da população abastecida dessa forma, esse valor é superior as demais formas de abastecimento, rede pública, carro pipa e cisternas (Tabela 2). Palivoda e Povaluck (2015) mencionam que as nascentes são importantes recursos utilizados no abastecimento de água para muitas comunidades.

Cruz et al. (2016) e Braga (2011) mencionam que no meio rural as nascentes desempenham um papel essencial no atendimento às demandas de água das populações rurais difusas, que não teriam condições de receber o abastecimento de água pelo sistema convencional público, em função das grandes distâncias dos centros de captação e tratamento das águas e em decorrência da dispersão espacial dos pontos de demanda.

O abastecimento das populações rurais difusas também está muito ligado às tecnologias desenvolvidas para facilitar a convivência com a seca como as cisternas, os açudes, os poços dentre outros, porém, eles acabam se tornando insuficientes uma vez que essas tecnologias dependem das precipitações que apresentam uma grande irregularidade, como afirmam Fiorezi et al. (2012) que dizem que essas fontes são altamente vulneráveis às secas, principalmente no segundo semestre do ano, que apresenta baixa pluviosidade e rios com vazões nulas, e por isso a maioria das fontes secam.

As populações difusas do Semiárido são as que dispõem de menos infraestrutura para enfrentar as adversidades do clima (CONTI; SCRHOEDER, 2013). Para Santana et al. (2011), no Semiárido, a falta de acesso à água produz efeitos graves, uma vez que a elevada proporção da população está localizada na zona rural onde se apresentam os mais baixos índices de desenvolvimento humano local.

Tabela 2. Abastecimento de água das famílias localizadas na zona rural do Semiárido Brasileiro, por UF

\begin{tabular}{|c|c|c|c|c|c|}
\hline UF & Total de domicílios & Rede pública & Poço ou Nascente & Carro pipa & Cisternas \\
\hline Alagoas & 67.760 & $29,7 \%$ & $32,7 \%$ & $9,1 \%$ & $28,5 \%$ \\
\hline Bahia & 524.731 & $38,2 \%$ & $40,1 \%$ & $3,7 \%$ & $18,0 \%$ \\
\hline Ceará & 372.437 & $38,3 \%$ & $45,3 \%$ & $3,0 \%$ & $13,3 \%$ \\
\hline Minas Gerais & 90.994 & $28,9 \%$ & $60,8 \%$ & $2,4 \%$ & $7,8 \%$ \\
\hline Paraíba & 131.427 & $19,4 \%$ & $48,4 \%$ & $12,4 \%$ & $19,7 \%$ \\
\hline Pernambuco & 273.735 & $27,1 \%$ & $40,5 \%$ & $8,5 \%$ & $23,8 \%$ \\
\hline Piauí & 100.341 & $24,8 \%$ & $53,8 \%$ & $3,7 \%$ & $17,6 \%$ \\
\hline Rio Grande do Norte & 102.530 & $43,4 \%$ & $29,7 \%$ & $11,8 \%$ & $15,1 \%$ \\
\hline Sergipe & 36.021 & $50,4 \%$ & $23,8 \%$ & $6,8 \%$ & $18,9 \%$ \\
\hline Total & 1.699 .976 & $33,9 \%$ & $42,6 \%$ & $5,7 \%$ & $17,7 \%$ \\
\hline
\end{tabular}

Fonte. Censo IBGE 2010. 
Dois fatos chamam atenção no Semiárido Alagoano, o primeiro é que as principais adutoras que o abastecem (adutora do Sertão, adutora da Bacia Leiteira e adutora do Agreste) captam suas águas da bacia do rio São Francisco, que há anos vem sendo fonte de discussão, pois passa por uma sobrecarga de usos já que é a principal fonte de abastecimento de muitos municípios em todo Semiárido Brasileiro, e a segunda é que boa parte do Semiárido Alagoano está inserido em uma área de elevado risco hídrico caracterizado por apresentar baixa precipitação anual, ausência de rios perenes e aquíferos sedimentares o que confere a essa região uma baixa segurança hídrica (Figura 2) (ANA, 2006).

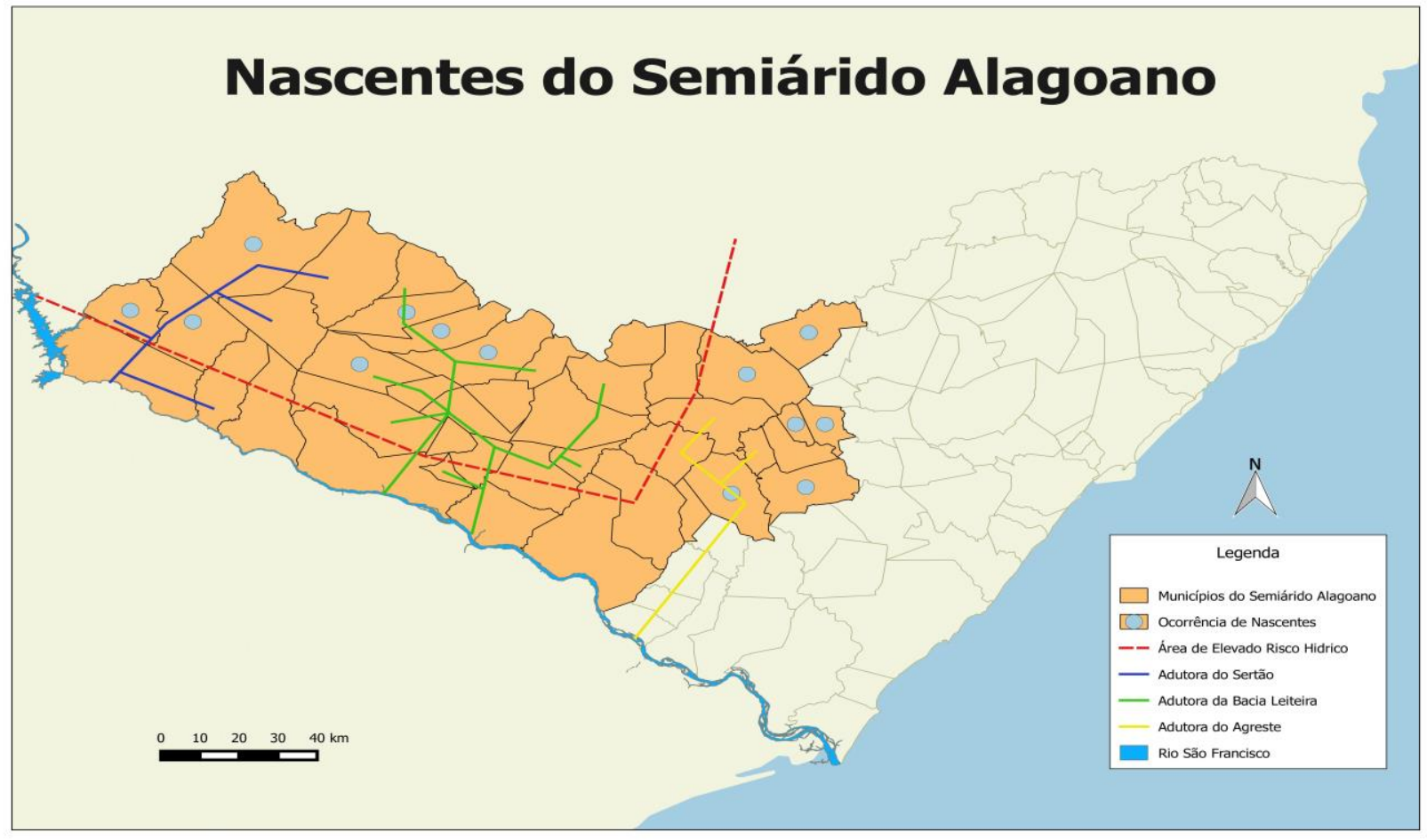

Figura 2. Mapa dos municípios com presença de nascentes. Fonte. Paulo Santos Neto.

Essa também é a área onde estão localizados os municípios com presença de nascentes, o que aumenta ainda mais a importância dessas nascentes para o abastecimento das populações difusas. Porém para que essas nascentes possam ser utilizadas como fonte de abastecimento faz-se necessário que elas ofereçam água em boa quantidade e qualidade para que seja garantida a qualidade de vida dessas populações, mas, não é isso que se percebe nas nascentes do Semiárido Alagoano, onde em sua maioria passam por processos de degradação intensa principalmente de matas ciliares pela falta de conhecimento dessas populações sobre a importância da preservação desses ambientes (Figura 3).

Segundo Felippe e Magalhães Junior (2012), as nascentes são consideradas pelo senso comum como ambientes equilibrados, inclusive, com água potável, muitos proprietários rurais 
utilizam a água de nascentes não apenas para irrigação ou dessedentação animal, mas também para consumo doméstico, porém, o uso e a ocupação do solo nas áreas de entorno, bem como os impactos derivados, podem alterar substancialmente a qualidade ambiental das nascentes.
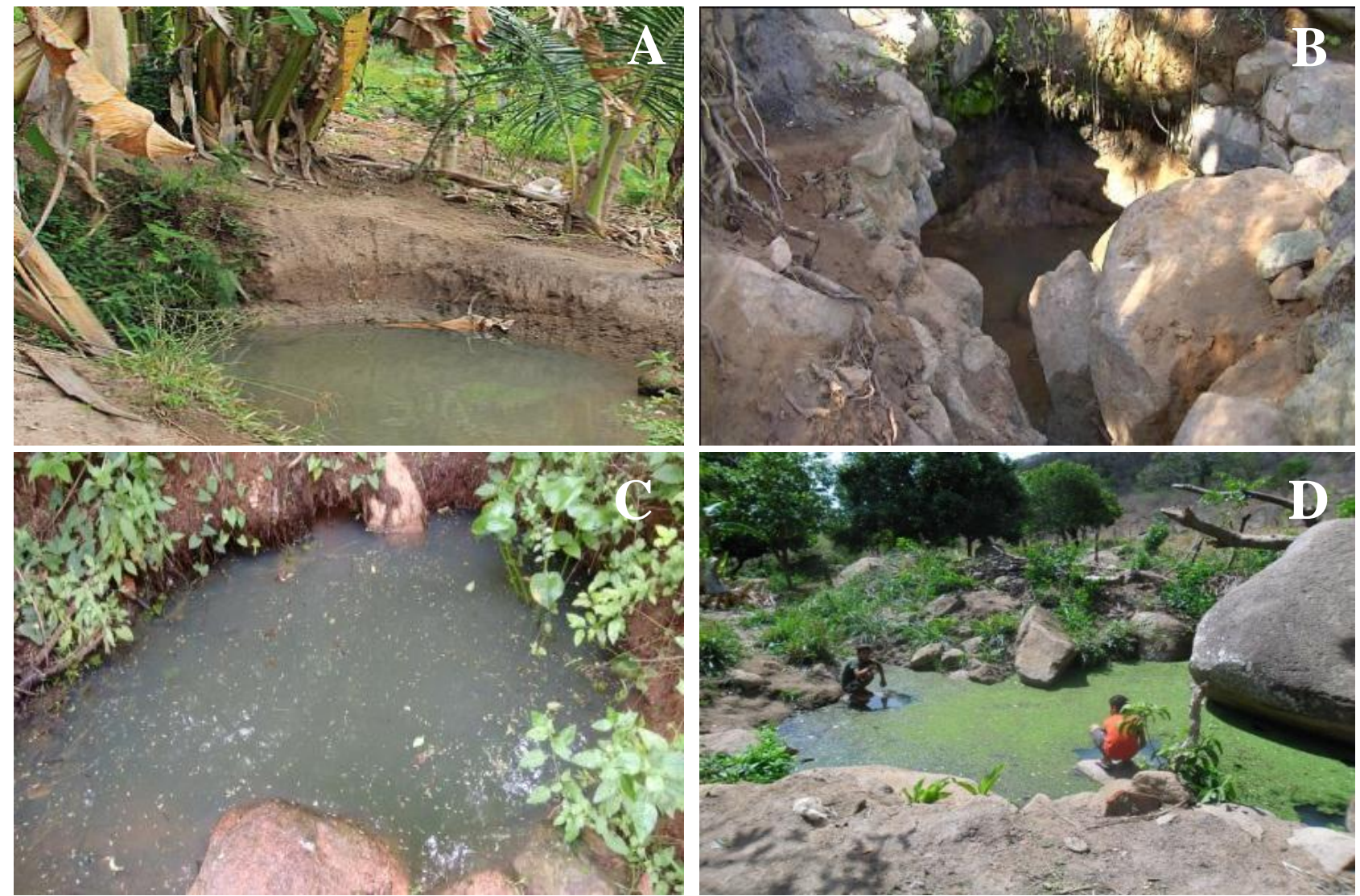

Figura 3. Nascentes no Município de Mata Grande (A), Município de Pariconha (B), Município de Água Branca (C), Município de Maravilha (D). Fonte. Leila Caroline Salustiano Silva e Projeto Re-nascer

Para entender a real importância no abastecimento humano por nascentes em Alagoas temos o exemplo do Município de Maravilha que no ano de 2010 após o rompimento da adutora foi abastecido durante três dias através de carros pipa pelas águas das nascentes da Serra da Caiçara (Figura 4A). Outro fato relatado por moradores mais antigos é que na década de 1970 durante um evento de seca severa muita gente só não morreu graças a uma nascente que tinha uma grande vazão e conseguiu suprir as necessidades da população, mas que hoje se encontra seca, segundo eles após uma modificação realizada em sua morfologia, o que fez com que ela fosse soterrada (Figuras 4B). Durante a pesquisa vários usuários dessas nascentes distribuídas pelo Estado afirmaram que além do abastecimento humano, eles também utilizam as águas das nascentes para irrigação de suas lavouras e dessedentação de seus rebanhos (Figura 4 C). 

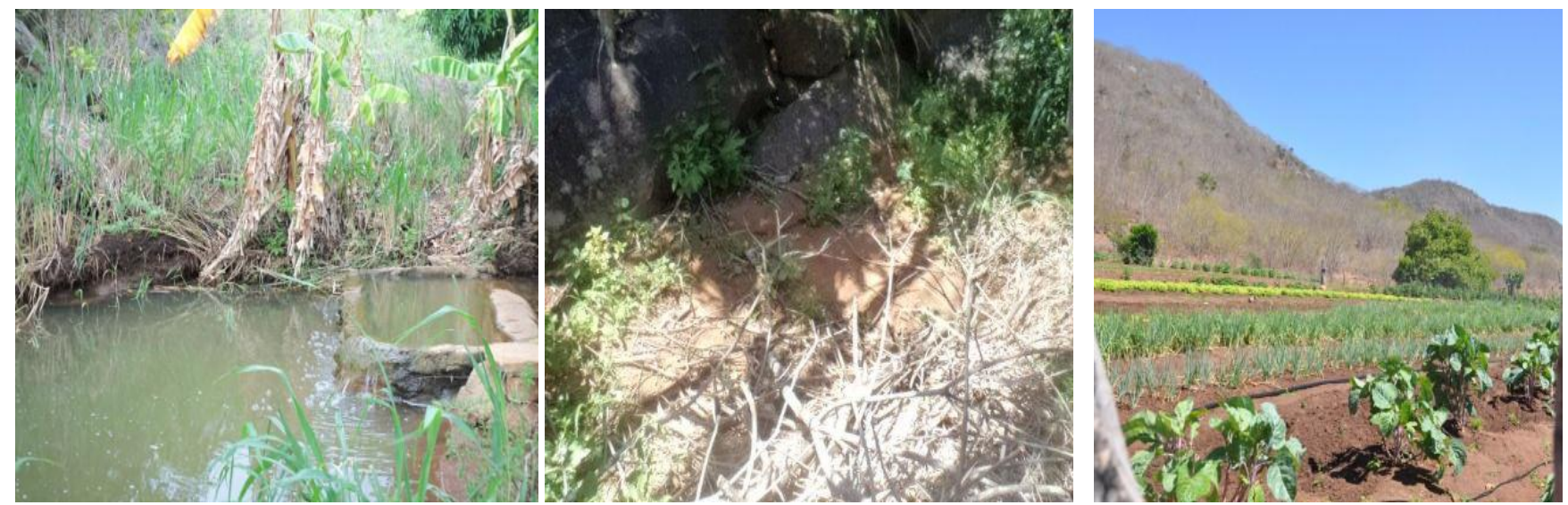

Figura 4. Nascente utilizada para o abastecimento (A), Nascente seca (B), Plantação irrigada pela água das nascentes (C). Fonte. Leila Caroline Salustiano Silva.

Além da importância social que essas nascentes desempenham, elas também possuem importância ambiental já que são fonte do surgimento dos rios, em Alagoas essas nascentes fazem parte das principais bacias hidrográficas do Estado como a Bacia do Rio São Miguel e Bacia do Rio Coruripe, além da Bacia do Rio Piauí que é o principal afluente perene do Rio São Francisco (Figura 5), portanto, é importante preserva-las e ir além, recuperando as que estejam em estado de degradação para se consiga a nascente ideal que Calheiros et al. (2009) é aquela que fornece água de boa qualidade, abundante e contínua, ressaltando além da quantidade de água produzida pela nascente, é desejável que tenha boa distribuição no tempo, ou seja, a variação da vazão situe-se dentro de um mínimo adequado ao longo do ano mantendo a vazão durante os períodos de seca.

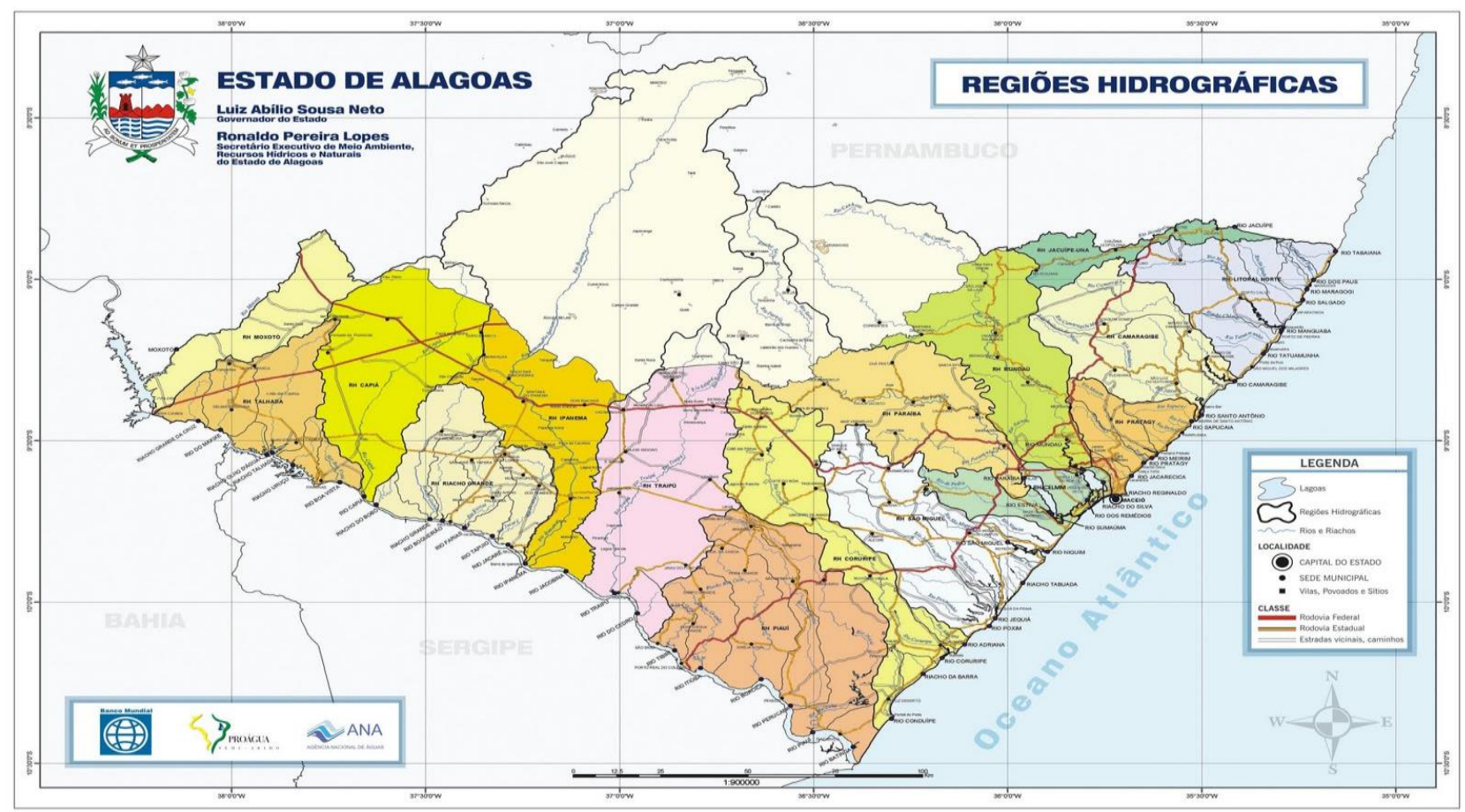

Figura 5. Mapa das regiões Hidrográficas de Alagoas. Fonte. SEMARH 


\section{CONSIDERAÇÕES FINAIS}

Inicialmente foram identificados 13 municípios do Semiárido Alagoano com presença de nascentes, onde se destacou o grande número de nascentes de vazão perene, o que permite seu uso pelas populações rurais difusas, inclusive nos períodos de seca. A utilização dessas nascentes nas comunidades se dá para diversas finalidades como pecuária, agricultura e consumo humano, porém, devido ao uso inadequado elas encontram-se em processo de degradação necessitando de políticas que visem sua preservação e recuperação.

Então torna-se estratégico para que haja o desenvolvimento rural a conservação das nascentes para que elas possam continuar desempenhando seu papel social de abastecimento humano das populações rurais difusas e também para que possam ser desenvolvidas atividades que gere renda para essas famílias como a agricultura. Essa conservação também deve se estender na busca pela qualidade desses ambientes para que elas também possam desenvolver seu principal papel o ambiental.

\section{REFERÊNCIAS}

AGÊNCIA NACIONAL DAS ÁGUAS. Atlas Nordeste: abastecimento urbano de água: alternativas de oferta de água para as sedes municipais da Região Nordeste do Brasil e norte de Minas Gerais. 1. ed. Brasília: ANA/SPR, 2006. 80 p.

ALVES, J. J. A. Biogeografia. João Pessoa: Editora Fotograf, 2008. 108 p.

ARAÚJO, G. J. F. de.; SILVA, M. M. da. Crescimento econômico no semiárido brasileiro: o caso do polo frutícola Petrolina/Juazeiro. Caminhos da Geografia. Uberlândia, v. 14, n. 46, p. 246-264. 2013.

BARROS, A. H. C. et al. Climatologia do Estado de Alagoas. 21. ed. Recife: Embrapa Solos, 2012. 32 p.

BRAGA, R. A. P. As nascentes como fonte de abastecimento de populações rurais difusas. Revista Brasileira de Geografia Física. Recife, v. 5, n. 5, p. 974-985. 2011.

CALHEIROS, R. O. et al. Cadernos da mata ciliar: Preservação e recuperação das nascentes de água e vida. 1. ed. São Paulo: 2009. 36 p.

CAMPOS, J. N. B. A evolução das políticas públicas no Nordeste. Brasília: CGEE, 2012. p. 26187.

CIRILO, J. A. Políticas públicas de recursos hídricos para o Semiárido. Estudos Avançados. São Paulo, v. 22, n. 63, p. 61-82. 2008.

CONTI, I. L.; SCRHOEDER, E. O. Estratégias de convivência com o semiárido brasileiro. 1. ed. Brasília: IABS, 2013. 208 p. 
CORDEIRO, J. M. P.; OLIVEIRA, A. G. Levantamento fitogeográfico em trecho de Caatinga hipoxerófila, sítio Canafístula, Sertãozinho, Paraíba, Brasil. Revista OKARA: Geografia em Debate. João Pessoa, v. 4, n.1-2, p. 54-65, 2010.

CRUZ, C. D. et al. Nascentes hídricas do município de cruz das almas enfoque na zona rural. In: IV CONGRESSO BAIANO DE ENGENHARIA SANITÁRIA E AMBIENTAL. 2016, Cruz das Almas. Anais... Cruz das Almas: 2016. p. 1-4.

EMBRAPA. Empresa Brasileira de Pesquisa Agropecuária. Solos do Nordeste. Recife: Embrapa Solos, 2014. 14 p.

EMBRAPA. Empresa Brasileira de Pesquisa Agropecuária. Sistema de classificação de solos. 2. ed. Rio de Janeiro: Embrapa Solos, 2006. 59 p.

FELIPPE, M. F.; MAGALHÃES JUNIOR, A. P. Impactos ambientais macroscópicos e qualidade das águas em nascentes de parques municipais em Belo Horizonte - MG. Revista Geografias. Belo Horizonte, v. 8, n. 2, p. 8-23. 2012.

FELIPPE, M. F.; MAGALHÃES JUNIOR, A.P. Consequências da ocupação urbana na dinâmica das nascentes em Belo Horizonte - MG. In: VI ENCONTRO NACIONAL SOBRE MIGRAÇÕES, 2009, Belo Horizonte. Anais... Minas Gerais, 2009. p. 1-19.

FIOREZE, A. P. A Questão da Água no Nordeste. Brasília: ANA/CGEE, 2012. 436 p.

GOMES, P. M.; MELO, C.; VALE, V. S. Avaliação dos impactos ambientais em nascentes na cidade de Uberlândia-MG: análise macroscópica. Revista Sociedade e Natureza, Uberlândia, v. 17, n. 32, p. 103-120. 2005.

GHEYI, H. R. et al. Recursos hídricos em regiões Semiáridas: estudos e aplicações. 1. ed. Paraíba/Bahia: INSA/UFRB, 2012. 258 p.

INSTITUTO BRASILEIRO DE GEOGRAFIA E ESTATÍSTICA. Dados de abastecimento urbano estados do Nordeste 2010. Disponível em: http://www.ibge.gov.br/. Acesso em: 12 jun. 2016, 16:02:53.

PALIVODA, A. P.; POVALUCK, M. Avaliação do estado de conservação de nascentes localizadas em áreas rurais do município de Itaiópolis-SC. Revista Saúde e Meio Ambiente. Mafra, v. 4, n. 1, p. 17-31. jan/jun. 2015.

RENAS-SER. Projeto Renascer. Disponível em: http://www.renas-ser.org/. Acesso em: 09 abr. 2016, 13:47:09.

SANTANA, V. L.; ARSKY, I. C.; SOARES, C. S. Democratização do acesso à água e desenvolvimento local: a experiência do Programa Cisternas no semiárido brasileiro. In: I CIRCUITO DE DEBATES ACADEMICOS, 2011, Brasília. Anais... Brasília: IPEA, 2011. p. 1-18.

SEMARH. Secretaria de Estado do Meio Ambiente e dos Recursos Hídricos. Alagoas em mapas. Disponível em: http://www.semarh.al.gov.br/. Acesso em: 25 jan. 2016. 
SEPLANDE. Secretaria de Estado do planejamento e Desenvolvimento Econômico. Perfil Municipal. 2. ed. Maceió: SEPLANDE/AL, 2014. 26 p.

SILVA, A. P. L. da.; FERREIRA FILHO, J. V.; SILVA, J. H. S. Estudo da vazão hídrica nas nascentes da Serra da Caiçara, município de Maravilha, Alagoas. Revista Reflexões e Práticas Geográficas. Maceió, v. 1, n. 1, p. 83-93. 2014.

VIEL, J. A. et al. Geotecnologias e aprendizagem espacial em ambiente educacional: o mapeamento de nascentes utilizando técnicas de geoprocessamento por meio de softwares livres. In: XVI SIMPÓSIO BRASILEIRO DE SENSORIAMENTO REMOTO, 2013, Foz do Iguaçu. Anais... Paraná: INPE, 2013. p. 2650-2656.

Recebido em: 14/08/2016

Aceito para publicação em: 01/10/2016 